\title{
Evaluating degree of pelvic pain and comparing it with the type and degree of adhesions in patients of Endometriosis
}

\author{
Tarini Sonwani ${ }^{1 *}$, Ratna Biswas ${ }^{2}$ \\ ${ }^{1}$ Ex- Resident, ${ }^{2}$ Professor, ${ }^{1,2}$ Dept. Obstetrics and Gynaecology, ${ }^{1,2}$ Lady Hardinge Medical College is a medical college Delhi, India
}

*Corresponding Author: Tarini Sonwani

Email: tanusonwani@gmail.com

Received: $4^{\text {th }}$ April, 2019

Accepted: $10^{\text {th }}$ May, 2019

\begin{abstract}
Introduction: Intra-abdominal adhesions are common features of endometriosis. Adhesions lead to several chronic symptoms including abdominal distension, pain, nausea, and abnormal bowel movement pattern. Adhesive disease may be life-altering in many patients.

Aims and Objectives: To study types of pain and compare it with type and degree of adhesion.

Materials and Methods: Thirty women diagnosed with endometriosis were studied. Pain intensity was assessed by visual analogue scale (VAS) and categorized as mild, moderate or severe accordingly. This was followed by laparoscopy/ laparotomy and staging of endometriosis which was done as per the American Society for Reproductive Medicine (ASRM) classification system. Corrective procedures were done simultaneously. Women were followed-up after 6 weeks to re-assess the pain intensity by using the same visual analogue scale (VAS).

Results: Mean age of study cohort was $30 \pm 5.75$ years. As per VAS, half of the patients had moderate pain (50\%). Forniceal thickening was present in $73.33 \%$ and cyst was felt in $66.66 \%$ women.76.66\% had unilateral cysts. Unilateral tubal adhesions were present in $76.66 \%$ women and bilateral adhesions were present in $23.33 \%$ women. Among the types of adhesions, flimsy adhesions were most common, being present in $76.66 \%$ women and deep adhesions were present in $20 \%$ women. Majority had $1 / 3^{\text {rd }}-2 / 3^{\text {rd }}$ tubal adhesions $(46.7 \%)$. All the ovarian adhesions were flimsy. Obliteration was present in $30 \%$ women. Forniceal thickening was reported in majority of the women with moderate pain $(93.3 \%)(p=0.001)$. Cyst was felt on per-vaginum examination in $80 \%$ women with severe pain. The correlation of degree of ovarian adhesions $(\mathrm{p}=0.003)$ and type and degree of tubal adhesions $(\mathrm{p}=0.004)$ with degree of pain by VAS in endometriosis was significant.

Conclusion: We found significant association between severity of pain and type of adhesions and between degree of tubal and ovarian adhesions and severity of pain. Operative procedures decrease the severity of pain.
\end{abstract}

Keywords: Tubal adhesions, Forniceal thickening, pain, visual analogue scale.

\section{Introduction}

There are multiple definitions of chronic pelvic pain (CPP). Previous reports have stressed upon the duration, its pattern and the location of pain to describe CPP. ${ }^{1,2}$ Howard gave a most satisfactory definition which state that non- menstrual pain which last for at least 3 months of duration, localizes to the anatomic pelvis and its extent that can cause functional disability and require medical or surgical treatment is called CPP. ${ }^{3}$

Adhesions describe the connections between opposing serosal and/or nonserosal surfaces of internal organs and the abdominal wall. The connection is visible at the site where should not be any. ${ }^{4}$ Adhesion can be in the form of band (vascular or avascular), can be filmy (transparent) and dense or opaque. It can also be cohesive connection without an intervening adhesion band. ${ }^{5}$

Role of intraabdominal pelvic adhesions to CPP is still a matter of research. Previous reports have shown adhesion as one of the etiologic factors for intestinal obstructions and infertility. ${ }^{6}$ In present study we hypothesize that adhesions could result in to pain. This occurs when adhesion causes distortion of normal anatomic relationships or during running or intercourse which causes stretching of the peritoneum at the attachment sites. In present study we tried to study the type of pain by dividing into mild moderate and severe and compared it with type and degree of adhesion.

\section{Materials and Methods}

We performed a prospective observational study on 30 women with endometriosis in Department of Obstetrics and Gynaecology in collaboration with Department of Radiology at Lady Harding Medical College and Smt. Sucheta Kriplani Hospital, New Delhi from November 2012 to March 2014

A series of 30 women, aged 20-49 years, diagnosed as having endometriosis by clinical history, abdominal and pelvic examination, trans vaginalsonography and colour Doppler were included in the study. Patients with other causes of pelvic pain and infertility like pelvic inflammatory disease, torsion ovarian cyst, ectopic pregnancy, or treatment with any kind of hormonal therapy (oral contraceptives, LH-releasing hormone analogues, clomiphene, or gonadotropins) in the previous 3 months were excluded. Written informed consent was taken from all women after explaining the nature of study.

Pain intensity was assessed by visual analogue scale (VAS). Pain intensity was scored from 0 to 10 , in which score 0 means no pain and 10 means worst pain. A score of 1-3, 4-6 and $\geq 7$ was classified as mild, moderate and severe pelvic pain respectively by looking at the facial expression of the patients (Wong Baker faces).

The abdomen was palpated to feel for any mass, its approximate size, its consistency, movable or fixed, whether 
tender or not. Per vaginum examination was done in all the women to assess the uterine version, size and mobility, cystic mass in the adnexa, presence of forniceal tenderness, thickening, nodularity and scarring and any thickening, scarring or nodularity over pouch of Douglas. Per-rectal examination was done to feel for any thickening, nodularity, scarring over pouch of Douglas and uterosacral ligaments.

All the patients underwent trans-vaginal sonography and colour Doppler and the site, size, and laterality were assessed. All the patients who underwent laparoscopy or laparotomy were assessed for the size, site, laterality of endometriomas, the degree and type of adhesions, superficial and POD obliteration. Surgical overview of entire abdominal cavity and pelvis was obtained. Entire uterus, fundus, its anterior surface, uterovesical pouch, posterior surface, pouch of Douglas, bilateral tubes and ovaries were examined for adhesions. All surfaces of ovary, ovarian fossae and tubes were visualized and any adhesions noted. Both the tubes were moved to see degree of mobility and to note fimbrial ovarian relationship. Fimbrial ends of fallopian tubes were assessed for complete enclosure.

Adhesions were graded as flimsy, moderate or dense whether they enclosed $1 / 3^{\text {rd }}, 1 / 3^{\text {rd }}-2 / 3^{\text {rd }}$ and $>2 / 3^{\text {rd }}$ of the tubes and ovaries respectively. Further the relationship of adhesions to the pelvic and various abdominal organs was noted. Abdominal structures like liver, its undersurface, spleen, mesentery, gut, enlarged nodes, and other abdominal organs were visualized for adhesion. Morphological features such as presence of superficial peritoneal endometriosis, ovarian endometriosis or deeply infiltrating endometriosis obliterating the cul-de-sac were noted.

Depending on the pelvic condition, two or more accessory ports were placed in the area of lower abdomen followed by adhesiolysis of existing adhesions, cystectomy or cyst drainage and electrocoagulation of cyst wall. Chromopertubation with methylene blue dye was also done to demonstrate the tubal patency in patients of infertility with endometriosis. Visual analog scoring was repeated 6 weeks post-operatively.

All the data analysis was performed using IBM SPSS ver. 20 software. Means and standard deviations were calculated for all continuous variables and chi square and ANOVA were used to determine statistically significant differences. Probability value less than 0.05 was set in order to determine significance.

\section{Results}

Mean age of study cohort was $30 \pm 5.75$ years. Majority of the women were in the age group of 25-29 years [11 (36.7\%)].Parity in women with endometriosis ranged from 0 to 4 . The mean parity was $1.10 \pm 1.24$. Out of 30 women with endometriosis, $15(50 \%)$ were nulliparous, $2(6.66 \%)$ women had only 1 child while $13(43.33 \%)$ women had 2 or more children.

All 30 women with endometriosis had symptoms of pain, while $15(50 \%)$ women had infertility and 6(20\%) women had abnormal uterine bleeding. Most common symptom in women with endometriosis was dysmenorrhoea followed by chronic pelvic pain and dyspareunia was the least common symptom. Out of 30 women, dysmenorrhoea was present in $22(73.33 \%)$ women, chronic pelvic pain was present in 17 (56.67\%) women and dyspareunia was present in 4(13.33\%) women.

Out of 30 women with endometriosis, 10 women $(33.3 \%)$ had mild pain, 15 women $(50 \%)$ had moderate pain and 5 women $(16.7 \%)$ had severe pain. Forniceal thickening was present in 22 women $(73.33 \%)$, cyst was felt in 20 women $(66.66 \%)$, uterine mobility was restricted in 11 women (36.66\%) and pouch of Douglas (POD) thickening was present in 10 women $(33.33 \%)$.

Out of 30 women with endometriotic cysts, 23(76.66\%) had unilateral cysts while the remaining $7(23.33 \%)$ had bilateral cysts. Unilateral tubal adhesions were present in 23(76.66\%) women and bilateral adhesions were present in $7(23.33 \%)$ women. Among the types of adhesions, flimsy adhesions were most common, being present in 23(76.66\%) women, isolated dense adhesions were present in only $1(3.33 \%)$ woman, while combination of flimsy and deep adhesions were present in $6(20 \%)$ women.

Less than $1 / 3^{\text {rd }}$ tubal adhesions were present in $6(20 \%)$ women, $1 / 3^{\text {rd }}-2 / 3^{\text {rd }}$ tubal adhesions were present in $14(46.7 \%)$ while more than $2 / 3^{\text {rd }}$ tubal adhesions were present in 10(33.3\%) women. All the ovarian adhesions were flimsy. Out of 30 women with endometriosis, ovarian adhesions were present in 6(20\%) women while absent in $24(80 \%)$ women. Less than $1 / 3^{\text {rd }}$ ovarian adhesions were present in only $1(3.3 \%)$ woman, $1 / 3^{\text {rd }}-2 / 3^{\text {rd }}$ ovarian adhesions were present in $3(10 \%)$ women and more than $2 / 3^{\text {rd }}$ ovarian adhesions were present in $2(6.7 \%)$ women.

Distribution of pouch of Douglas (POD) obliteration in women with endometriosis showed that partial obliteration was present in $9(30 \%)$ women while complete obliteration was present in $6(20 \%)$ women.

Out of 10 women with mild pain, 7(70\%) had unilateral cysts while $3(30 \%)$ had bilateral cysts. Out of 15 women with moderate pain, $13(86.7 \%)$ women had unilateral cysts while $2(13.3 \%)$ had bilateral cysts. Out of 5 women with severe pain, $3(60 \%)$ women had unilateral cysts while $2(40 \%)$ had bilateral cysts. The correlation of cyst laterality with degree of pain by visual analogue scale in endometriosis was not significant $(\mathrm{p}=0.394)$.

Out of 30 women, ovarian adhesions were present in only 6 and all of them had flimsy adhesions. In women with moderate and severe pain, the adhesions were mostly between $1 / 3-2 / 3^{\text {rd }}$ and $>2 / 3^{\text {rd }}$. The correlation of degree of ovarian adhesions with severity of pain was statistically significant $(\mathrm{p}=0.003)$.

Out of 30 women with endometriosis, adhesiolysis was done in $22(73.33 \%)$ women, chromopertubation was done in $15(50 \%)$ women, cyst excision was done in $13(43.33 \%)$ women, cyst drainage and electrocoagulation of cyst wall was done in $12(40 \%)$ women while hysterectomy was done in $3(10 \%)$ women. 
Table 1: Correlation of clinical findings with degree of pain by visual analogue scale (vas) in women with endometriosis

\begin{tabular}{|c|c|c|c|c|c|c|}
\hline \multicolumn{2}{|l|}{ Clinical findings } & Mild $(n=10)$ & Moderate $(n=15)$ & Severe $(n=5)$ & Total & P value \\
\hline \multirow{2}{*}{ Forniceal thickening } & Present & $3(30)$ & $14(93.3)$ & $5(100)$ & 22 & \multirow{2}{*}{0.001} \\
\hline & Absent & $7(70)$ & $1(6.7)$ & $0(0)$ & 8 & \\
\hline \multirow{2}{*}{ Cyst in per-vaginum } & Present & $6(60)$ & $10(66.7)$ & $4(80)$ & 20 & \multirow{2}{*}{0.741} \\
\hline & Absent & $4(40)$ & $5(33.3)$ & $1(20)$ & 10 & \\
\hline \multirow{2}{*}{ Uterine mobility restricted } & Present & $0(0)$ & $7(46.7)$ & $4(80)$ & 11 & \multirow{2}{*}{0.005} \\
\hline & Absent & $10(100)$ & $8(53.3)$ & $1(20)$ & 19 & \\
\hline \multirow{2}{*}{ POD thickening } & Present & $1(10)$ & $5(33.3)$ & $4(80)$ & 10 & \multirow{2}{*}{0.025} \\
\hline & Absent & $9(90)$ & $10(66.7)$ & $1(20)$ & 20 & \\
\hline
\end{tabular}

Data is expressed as no of patients (percentage), $n$; number of patients

Table 2: Correlation of tubal adhesions with degree of pain by visual analogue scale in endometriosis

\begin{tabular}{|c|c|c|c|c|}
\hline \multirow{2}{*}{ Type and degree of tubal adhesions } & \multicolumn{3}{|c|}{ Degree of pain by VAS } & \multirow{2}{*}{$P$ value } \\
\hline & Mild & Moderate & Severe & \\
\hline Flimsy $(n=23)$ & $10(100)$ & $12(80)$ & $1(20)$ & \multirow{3}{*}{0.004} \\
\hline Dense $(n=1)$ & $0(0)$ & $1(6.7)$ & $0(0)$ & \\
\hline Both $(\mathrm{n}=6)$ & $0(0)$ & $2(13.3)$ & $4(80)$ & \\
\hline$<1 / 3^{\text {rd }}(n=6)$ & $6(60)$ & $0(0)$ & $0(0)$ & \multirow{3}{*}{0.004} \\
\hline $1 / 3-2 / 3^{\text {rd }}(n=14)$ & $3(30)$ & $8(53.3)$ & $3(60)$ & \\
\hline$>2 / 3^{\text {rd }}(\mathrm{n}=10)$ & $1(10)$ & $7(46.7)$ & $2(40)$ & \\
\hline
\end{tabular}

Data is expressed as no of patients (percentage), n; number of patients

Table 3: Correlation of degree of ovarian adhesions with degree of pain by visual analogue scale in endometriosis

\begin{tabular}{|c|c|c|c|c|}
\hline \multirow{2}{*}{ Ovarian adhesions (degree) } & \multicolumn{3}{|c|}{ Degree of pain by VAS } & \multirow{2}{*}{$P$ value } \\
\hline & Mild $(n=10)$ & Moderate $(n=15)$ & Severe $(n=5)$ & \\
\hline Absent $(n=24)$ & $10(100)$ & $3(86.7)$ & $1(20)$ & \multirow{4}{*}{0.003} \\
\hline$<1 / 3^{\text {rd }}(\mathrm{n}=1)$ & $0(0)$ & $1(6.7)$ & $0(0)$ & \\
\hline $1 / 3-2 / 3^{\text {rd }}(n=3)$ & $0(0)$ & $1(6.7)$ & $2(40)$ & \\
\hline$>2 / 3^{\text {rd }}(\mathrm{n}=2)$ & $0(0)$ & $0(0)$ & $2(40)$ & \\
\hline
\end{tabular}

Data is expressed as no of patients (percentage), n; number of patients

All $10(100 \%)$ women who had mild pain preoperatively reported no pain on follow-up. Out of 15 women with moderate pain, $8(53.3 \%)$ women reported no pain while 7 (46.7\%) reported mild pain. All the patients with severe pain reported mild pain. This difference in pre- and post-operative pain was statistically significant ( $\mathrm{p}$ value $0.001)$.

\section{Discussion}

In the present study mean age was $30 \pm 5.75$ years. Majority of women $(36.7 \%)$ with endometriosis were in the age group of 25-29 years. In a study by Hajialioghlo et al, the age ranged between 16-43 years, with the maximum number of women with endometriosis being in 30-35 years of age group and the mean age was $30.55 \pm 5.54$ years. ${ }^{7}$ In another study by Chapron et al, the age ranged between 17-41 years and the mean age was $31.9 \pm 5.2$ years. $^{8}$ In a study by Holland et al, the age range of women with endometriosis was between 19-50 years and the mean age was 35.0 \pm 7.10 years. ${ }^{9}$ Both the studies are in agreement to present study findings.

Out of 30 women with endometriosis, $50 \%$ were nulliparous, while $43.33 \%$ women had $\geq 2$ children. Similar to present study findings Vercellini et al reported $70.7 \%$ women were nulliparousand $12.6 \%$ women had $\geq 2$ children. ${ }^{10}$ In studies by Chapron et al, the percentage distribution of nulliparous, women with 1 child and $\geq 2$ children were $73.7 \%, 16 \%$ and $10.3 \%$ respectively. ${ }^{8}$

In the present study, women with endometriosis presented with three types of pain i.e., dysmenorrhoea, dyspareunia and chronic pelvic pain. The symptoms were in combination. Majority felt moderate pain and severe pain in present study. In agreement to present study Somigliana E et al also reported dysmenorrhoea as the most common associated pain in $77.4 \%$ of women with endometriosis, dyspareunia was present in $46.2 \%$ of women while chronic pelvic pain was present in $51.6 \%$ of women. ${ }^{11}$ In a study by Holland et al (Holland TK 2013), the distribution of dysmenorrhoea, dyspareunia and chronic pelvic pain was $72.2 \%, 45.9 \%$ and $49.5 \%$ respectively. ${ }^{9}$ In a study by Dai et al, dysmenorrhoea, chronic pelvic pain and dyspareunia comprised of $61.6 \%, 20.3 \%$ and $21.5 \%$ respectively. ${ }^{12}$

In the present study, apart from pain, women with endometriosis also presented with infertility and abnormal uterine bleeding, which comprised of 50\% and $20 \%$ respectively. In a study by Somigliana et $\mathrm{al}^{11}$, infertility was present in $37.6 \%$, whereas in a study by Chapron et $\mathrm{al}^{8}$, it was present in $38.7 \%$.

Incidence of bilateral endometriotic cysts in women with mild, moderate and severe pain was $30 \%, 13.3 \%$ and 
$40 \%$ respectively. This shows that laterality had no association with severity of pain. In studies by Chapron et $\mathrm{al}^{8}{ }^{8}$ Holland et $\mathrm{al}^{9}$ and Vercellini et $\mathrm{al}^{10}$, the incidence of bilateral cysts were 26\%, $12 \%, 47.1 \%$ and $61.5 \%$ respectively.In a study by Dai et al ${ }^{12}$, bilateral endometriotic cysts were not related to chronic pelvic pain ( $p>0.05)$. In another study by Chapron et $\mathrm{al}^{8}{ }^{8}$ bilateral endometriotic cysts were associated with dysmenorrhoea $(\mathrm{p}=0.008)$ and with chronic pelvic pain $(\mathrm{p}=0.003)$ but not associated with dyspareunia $(\mathrm{p}=0.166)$.

We observed that moderate pain was seen in women with flimsy adhesions but the degree of tubal involvement was more $\left(1 / 3^{\text {rd }}-2 / 3^{\text {rd }}\right.$ or $>2 / 3^{\text {rd }}$ in all the women whereas in women with mild pain, although the adhesions were flimsy, the degree of tubal involvement was less than $1 / 3$. We also found that severity of pain increased with increasing density of adhesions and with greater degree of tubal involvement.

Incidence of ovarian flimsy adhesions was $20 \%$ which was present between ovary and pelvic side wall and posterior peritoneum. We also found a significant correlation between degree of ovarian adhesions and severity of pain. Somigliana et $\mathrm{al}^{11}$ and Parazzini et $\mathrm{al}^{13}$ reported that the incidence of pelvic adhesions was $74.2 \%$ and $81.9 \%$ respectively. Chapron et $\mathrm{al}^{8}$ found that adhesions were associated with dysmenorrhoea while they had no correlation with dyspareunia and chronic pelvic pain. In a similar study by Parazzini et $\mathrm{a}^{13}$ reported that frequency of adhesions was lower in stage I-II (65\%) and higher in women with stage III-IV $(88 \%)(\mathrm{p}=0.01)$. The presence of adhesions was associated with higher mean VAS (visual analogue scale) in women with ovarian endometriosis and with stage I-II disease. Women with ovarian adhesions reported higher pain score ( $p$ value $<0.05$ ) than women with peritoneal adhesions or adhesions in other sites. This is similar to present study findings. Similar to present study Porpora et $\mathrm{al}^{14}$ also reported that size of endometrioma had no association with pain while it was the presence of adhesions that causes pain.

After appropriate procedures, women were followed up after 6 weeks to assess pain by visual analogue scale. Preoperatively, there were $33.33 \%$ women with mild pain, $50 \%$ with moderate pain and $16.66 \%$ with severe pain. While post-operatively, there were $60 \%$ women who reported no pain and $40 \%$ women reported mild pain and none reported moderate to severe pain. This difference in follow up pain was statistically significant $(\mathrm{p}=0.001)$. This suggests that operative procedures decrease the severity of pain. Cross sectional nature and small sample size were the mail limitations of present study. A large randomized clinical trial is needed to strengthen our results.

\section{Conclusion}

Severity of pain correlated with type of adhesions being more commonly associated with dense adhesions as compared to flimsy adhesions. Positive correlation was observed between degree of tubal and ovarian adhesions and severity of pain suggesting that pain increased with greater involvement of tubes and ovaries. We also found that operative procedures decrease the severity of pain.

\section{Conflict of Interest: None.}

\section{References}

1. Malik E, Berg C, Meyhofer-Malik A, Haider S, Rossmanith WG. Subjective evaluation of the therapeutic value of laparoscopic adhesiolysis. Surg Endosc 2000;14:79 - 81.

2. Brichant G, Denef M, Tebache L, Poismans G, Pinzauti S, Dechenne $\mathrm{V}$ et al. Chronic pelvic pain and the role of exploratory laparoscopy as diagnostic and therapeutic tool: a retrospective observational study. Gynecol Surg 2018;15(13):1-7.

3. Howard FM. The role of laparoscopy in chronic pelvic pain: promise and pitfalls. Obstet Gynecol Surv 1993;48:357- 87.

4. Morrissey D, Ginzburg N, Whitmore K. Current advancements in the diagnosis and treatment of chronic pelvic pain. Curr Opin Urol 2014;24:336-44

5. Zondervan KT, Yudkin PL, Vessey MP, Dawes MG, Barlow $\mathrm{DH}$, Kennedy $\mathrm{SH}$ et al. Patterns of diagnosis and referral in women consulting for chronic pelvic pain in UK primary care. Br J Obstet Gynaecol 1999;106:1156-61

6. Berkley KJ, Rapkin AJ, Papka RE. Pains Endometriosis. Sci 2005; 308(5728):1587-9.

7. Hajialioghlo P, Ghatresamani F, Nariman N, Sobhani N. Color Doppler Ultrasound Indices in Endometriotic Cysts. Am J Appl Sci 2009;6(10):1776-80.

8. Chapron C, Dubuisson JB, Fritel X, Rambaud D. Diagnosis and management of organic ovarian cysts: Indications and procedures for laparoscopy. Hum Reprod Update 1996; 2: 43546.

9. Holland TK, Cutner A, Saridogan E, Mavrelos D, Pateman K, Jurkovic D. Ultrasound mapping of pelvic endometriosis: does the location and number of lesions affect the diagnostic accuracy? a multicentre diagnostic accuracy study. $B M C$ Womens Health 2013;13: 43.

10. Vercellini P, Buggio L, Somigliana E, Barbara G, Viganò P, Fedele L. Attractiveness of women with rectovaginal endometriosis: a case-control study. FertilSteril 2013;99(1):212-8.

11. Somigliana E, Paola Viganò, Massimo Candiani, Irene Felicetta, Anna Maria Di Blasio, Mario Vignali et al. Use of serum-soluble intercellular adhesion molecule-1 as a new marker of endometriosis 2002; 77 (5):1028-31.

12. Dai Y, Leng JH, Lang JH, Liu ZF, Li XY, Wang YY et al. Clinico-pathologic characteristics of posterior deeply infiltrating endometriosis lesions, pain symptoms and its treatment using laparoscopic surgery. Zhonghua Fu Chan KeZaZhi 2010;45(2):93-8.

13. Parazzini F, Chiaffarino F, Surace M, Chatenoud L, Cipriani S, Chiantera V et al. Selected food intake and risk of endometriosis. Human Repro duction 2004;19(8):1755-9.

14. Porpora MG, Koninckx PR, Piazze J, Natili M, Colagrande S, Cosmi EV et al. Correlation between endometriosis and pelvic pain. J Am Assoc Gynecol Laparosc 1999;6(4):429-34.

How to cite this article: Sonwani T, Biswas R, Evaluating degree of pelvic pain and comparing it with the type and degree of adhesions in patients of Endometriosis. Indian $J$ Obstet Gynecol Res 2019;6(2):169-172. 